beginning, have a tendency after a time to increase the frequency of the emitted note because of the heating produced by the breath of the player. Finally, string instruments allow the player within certain limits to follow the tune of other instruments, and the same is the case with singers.

No evidence was found to confirm the generally stated order of variation in which the mean tuning frequency tends to increase during the execution of selections by an orchestra. The frequency of the pitch which is observed during the tuning of instruments before starting the performance tends to be maintained as a mean value during the whole performance. As few tests of this have been made, it would be advisable to make further investigations; if confirmed, it would be of importance in relation to the choice of the steps apt to modify the tuning frequency.

\title{
TEMPORARY PRESERVATION OF ANIMAL SPECIMENS
}

$\mathrm{M}^{\mathrm{s}}$

R. J. R. NORMAN, of the British Museum (Natural History), has abstracted and translated the following from a letter he has recently received from Dr. Paul Chabanaud, of the Museum National d'Histoire Naturelle, Paris :

On learning the news of the sensational discovery of Latimeria chalumnae ${ }^{1}$, there can be, I imagine, few naturalists who were not seriously perturbed by the thought that it was only by the merest chance that this extraordinary living fossil was not irretrievably lost. Indeed, our congratulations are due to all those who have succeeded in saving this priceless specimen, although we must deplore the fact that its final state of preservation is so far from satisfactory.

Even if fishermen do not often find a representative of the Mesozoic fauna in their nets, how very few of the interesting specimens captured by them daily throughout the world find their way to our museums or laboratories. Even in the case of the species wellknown to science, the larger individuals are rarely, if ever, preserved, and our knowledge of the size attained by certain animals (for example, the halibutHippoglossus hippoglossus (L.); some of the Siluroids; and very many Elasmobranchs) rests largely upon hearsay, or upon the exammation of fragments (for example, the 'saws' of Pristis).

Naturalists travelling abroad are compelled to forgo the collection of individuals exceeding a certain size (except in the form of skins), solely because their preservation by ordinary methods (alcohol or formalin) necessitates the use of containers so large that their transport is quite impracticable.

There is, however, an extremely simple and quite inexpensive method of preserving animals, both large and small, and in particular fishes: this is by the use of sodium chloride or sea salt. I speak with some knowledge on this subject, as I have used the method myself on many occasions.

All that is necessary is to place the animal in a basin or dish, or preferably on a board or something of a like nature, and to cover it with a heap of salt, being careful to introduce as much of the salt as possible into the mouth and gills, as well as into the abdominal cavity through an incision previously made in one side of the body. The effect of the salt, of course, is to absorb the fluids from the organism. After some hours, that is to say, on the next day at the latest, the specimen should be turned over, drained, and the diluted salt replaced by fresh.

If the animal is of small or moderate size no further treatment is usually required, but if of considerable volume it may be necessary to repeat the operation several times, care being taken to turn the body over each time. Naturally, the hygrometric state of the surrounding atmosphere will tend to accelerate or retard the process as the case may be.

The desiccation of the specimen must be made as complete as possible, since, of course, the sodium chloride does not fix the tissues, and its preserving powers depend entirely upon its strong hydrophilism, the organic tissues treated by the salt being dehydrated and at the same time rendered unsuitable for the proliferation of destructive organisms such as bacteria, moulds, etc.

Thus, it is absolutely indispensable, especially in warm and humid climates, to obtain this dehydration as rapidly as possible, the animal being, in fact, converted into a 'stock-fish', which can be readily packed in any sort of box or crate, with no other packing than the salt itself.

By using this method I have been able to obtain very large specimens of fishes (for example, Psettodes belcheri Bennett, a flatfish from the north-west coasts of Africa, and enormous heads of halibut from Newfoundland), which would have been extremely difficult, if not impossible, to procure otherwise.

When the specimen reaches the museum or laboratory it should be soaked in fresh water for just long enough for it to resume its natural form; after this, it can be finally immersed in alcohol or formalin. The complete elimination of the salt is quite unnecessary, since its presence does not harm the final preservation.

I have never experimented myself with a mixture of sodium chloride and sodium sulphate, although I understand that this has given excellent results.

Clearly, this method of salting does not represent the ideal treatment for histological examination, but $I$ can assure you that, not only the external morphology, but even the macroscopic anatomy, is perfectly clear ; external characters, bones, viscera, muscles and nerves can all be easily studied. Obviously, the same cannot be said with regard to the blood-vessels or the brain, since special treatment is usually required before undertaking research on these organs.

I do not pretend that the external shape of a salted fish will always compare favourably with that of one which has been placed while fresh in alcohol or formalin. The colours are altered; frequently the scales are displaced. Admittedly the salt is only a makeshift, but how very much better than putrefaction and complete ruin?

I have dealt only with fishes, but there is nothing to prevent the use of salt for the preservation of any kind of vertebrate, provided that such necessary precautions as cutting open the peritoneum and the stomach, etc., are taken.

NATURE, 143, 455 (1939). 